\title{
Chiral Tartaric Acid Improves Fracture Toughness of Bioactive Brushite-Collagen Bone Cements
}

\author{
Stylianos O. Sarrigiannidis, Hanan Moussa, Oana Dobre, Matthew J. Dalby, Faleh Tamimi, \\ and Manuel Salmeron-Sanchez*
}

Cite This: ACS Appl. Bio Mater. 2020, 3, 5056-5066

Read Online

\section{ACCESS | Lلll Metrics \& More | 回 Article Recommendations | S1 Supporting Information}

ABSTRACT: Brushite cements are promising bone regeneration materials with limited biological and mechanical properties. Here, we engineer a mechanically improved brushite-collagen type I cement with enhanced biological properties by use of chiral chemistry; D- and L-tartaric acid were used to limit crystal growth and increase the mechanical properties of brushite-collagen cements. The impact of the chiral molecules on the cements was examined with Fourier-transform infrared spectroscopy (FTIR), Xray diffraction (XRD), and scanning electron microscopy (SEM). A 3-point bend test was utilized to study the fracture toughness, and cell attachment and morphology studies were carried out to demonstrate biocompatibility. XRD and SEM analyses showed that

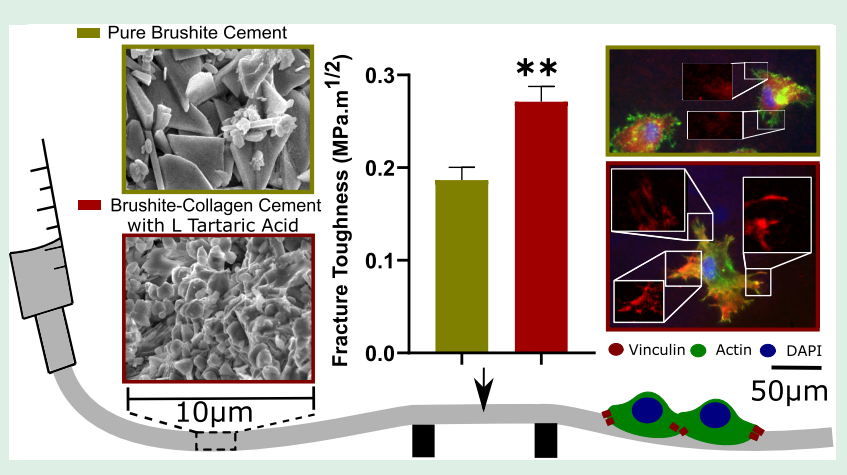
L-, but not D-tartaric acid, significantly restrained brushite crystal growth by binding to the $\{010\}$ plane of the mineral and increased brushite crystal packing and the collagen interaction area. $\mathrm{L}$ Tartaric acid significantly improved fracture toughness compared to traditional brushite by $30 \%$. Collagen significantly enhanced cell morphology and focal adhesion expression on L-tartaric acid-treated brushite cements.

KEYWORDS: collagen, brushite, chiral molecules, bone regeneration, bone cements, tartaric acid

\section{INTRODUCTION}

The need for bone tissue replacements has grown significantly in recent years with supply not meeting demand. Autografts are limited, and allografts or transplants face issues such as disease transmission or immune rejection. ${ }^{1-4}$ Synthetic biomaterials such as bioceramics can overcome these issues. ${ }^{1,2,4}$ This has particular relevance for high-load-bearing applications, e.g., in maxillofacial reconstruction, as they are similar in composition to the inorganic-mineral component of bone ${ }^{5}$ and have shown good mechanical properties as well as biocompatibility in vitro and in vivo. ${ }^{6-10}$ Ideally the implanted biomaterial should degrade gradually with time, thus providing space for new tissue ingrowth, ${ }^{11}$ yet keep its load-bearing properties until new bone takes over its natural function.

Hydroxyapatite (HA)-based materials have become gold standard bioceramics despite being nondegradable ${ }^{12,13}$ in vivo. There are other promising materials like $\alpha$ - and $\beta$-tricalcium phosphate (TCP), but their resorption is too fast and nonuniform, respectively. ${ }^{9,14,15}$ Dicalcium phosphate dihydrate (DCPD), also known as brushite, is a promising alternative with both good resorbability in vivo and good biocompatibility. ${ }^{7,16}$ However, brushite materials, similar to other bioceramics, are brittle and prone to in vivo mechanical failure. ${ }^{17}$ This can lead to particle release causing inflammation and deep vein thrombosis in extreme cases. ${ }^{18,19}$
In native bone, collagen (mainly type I), a ubiquitous mineralizable protein, compensates for the brittleness of its inorganic, mineral phase $\mathrm{s}^{20,21}$ and imparts strength and toughness to the native tissue. ${ }^{22}$ Studies suggest that damage to the collagen triple helix due to either radiation or a genetic disorder such as osteogenesis imperfecta (a gene mutation leading to incorrect formation of $\alpha$ collagen chains) has detrimental effects on the mechanical properties of bone. ${ }^{23}$ Collagen also promotes cell attachment and proliferation ${ }^{24-27}$ through integrin binding $(\alpha 1 \beta 1, \alpha 2 \beta 1, \alpha 10 \beta 1$, and $\alpha 11 \beta 1)$ to the GFOGER sequences of collagen. ${ }^{28}$ Integrin-collagen interactions are vital as they allow cells to interact with their surroundings, which induces intracellular signaling directing cell behavior (e.g., differentiation, contractility, and motility). ${ }^{24,28}$ Collagen-bioceramic composites have been primarily produced in the form of spongelike scaffolds, which, despite their impressive biological properties and high ductility, are not strong and stiff enough for high-load-bearing applica-

Received: May 13, 2020

Accepted: July 6, 2020

Published: July 6, 2020 


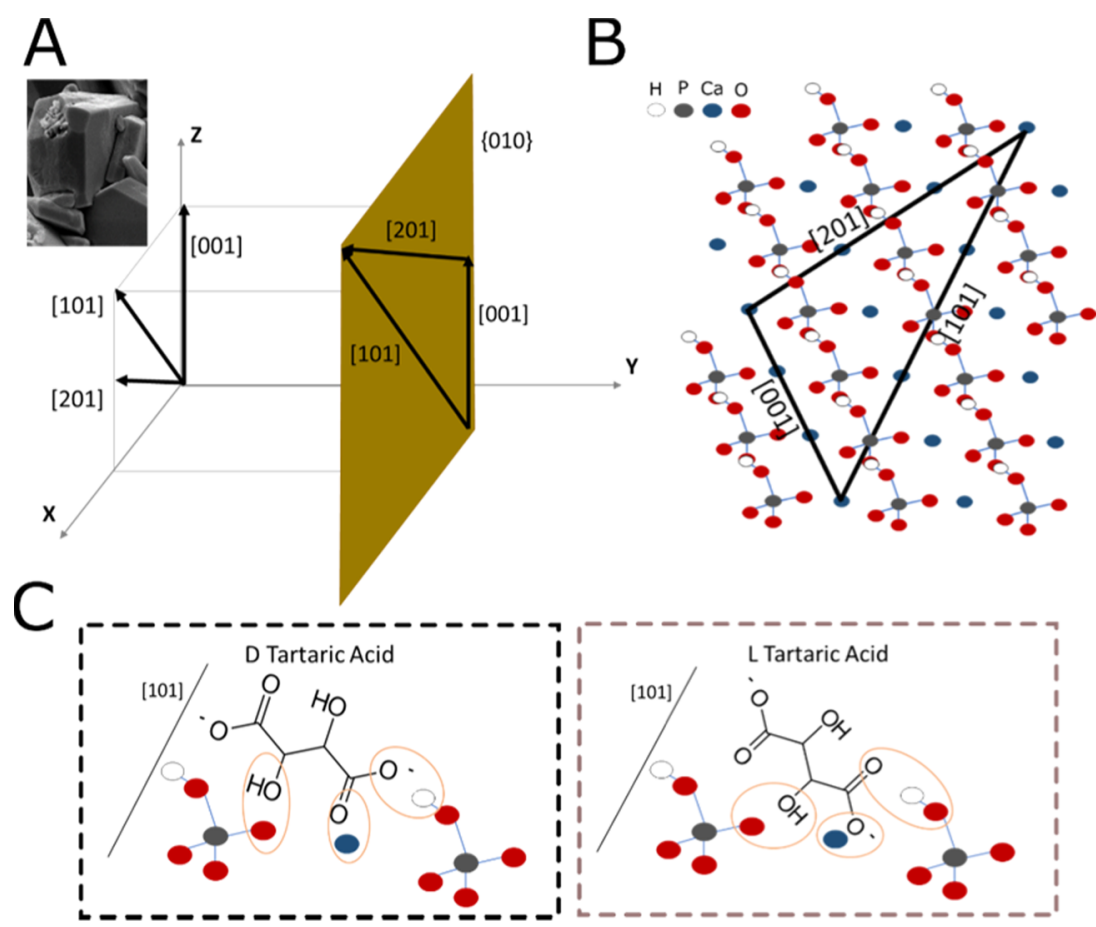

Figure 1. Theory of the selective effect of chiral Tar on crystallization of brushite crystals based on previous findings: ${ }^{18}$ (A) Dynamic growth steps of brushite [001, 101, and 201] and its $\{010\}$ plane represented on a cubic unit cell. (B) Representation of the atomic arrangement within the mineral. (C) Binding of $\mathrm{D}-(-)$ and $\mathrm{L}-(+)-$ Tar to the [101] growth step of brushite. The carboxyl group of tartaric acid interacts with calcium (hydrogen bond) and $\mathrm{HPO}_{4}$ (hydrogen bond). The hydroxyl group of tartaric acid forms another hydrogen bond with $\mathrm{HPO}_{4}$. The hydroxyl group to the carboxyl group determines the strength of the Tar-brushite interaction, the closer the better, due to bond resonance. Thus, L- $(+)-$ Tar, unlike D-(-)-Tar, binds stronger and inhibits [101] dynamic strep growth.

tions. $^{24-26,29}$ To date, only one study has attempted to produce high-strength collagen-bioceramic cements. ${ }^{17}$ However, despite showing increased cell attachment compared to plain brushite, the mechanical properties did not improve in wet conditions as would be found in the body. ${ }^{17}$ Therefore, there is an increased demand to develop resorbable bioceramic-based materials, which are more resistant to mechanical failure but can interact with cells to direct their behavior and initiate implant to bone remodeling.

The mechanical properties of bone can be largely attributed to nanosized mineral particles and collagen fibers forming a staggered structure at the sub-nanometer level, which are the building blocks of the hierarchically structured bone tissue. ${ }^{30-32}$ Noncollagenous proteins (NCPs), particularly those belonging to the small integrin-binding ligand, N-linked glycoprotein (SIBLING) family, e.g., osteopontin and bone sialoprotein 2, are known to control bone mineral size and regulate intra- and interfibrillar mineralization. ${ }^{33-36}$ Recent studies suggest that matrix proteins composed of chiral Lamino acids play an important mineral modulatory role and control mineral crystal nucleation, growth, and morphology of bioceramics through chiral recognition. ${ }^{37,38}$ It is suggested that $\alpha$-hydroxy carboxyl acid groups recognize the [101] dynamic step of brushite crystal growth, ${ }^{18,38}$ allowing compounds such as $\mathrm{L}-(+)$-tartaric acid ( $\mathrm{L}-(+)$-Tar), already used in the pharmaceutical industry, to have a similar mineralization modulatory role, ${ }^{18,37,38}$ which enhances the mechanical properties of bioceramics. ${ }^{18}$

Brushite mineralization involves three dynamic steps along the $[101,001]$, and [201] directions, which grow evenly. The even growth of crystals is retained when $\mathrm{D}-(-)$-tartaric acid (D(-)-Tar) is added. However, L-(+)-Tar interacts strongly with the dynamic step $[101](\{020\}$ crystal plane $)$ and limits brushite crystal size. ${ }^{18}$ According to computer simulations, tartaric acid has three interaction sides with brushite: a carboxyl group of the tartaric acid interacts with calcium (hydrogen bond) and $\mathrm{HPO}_{4}$ (hydrogen bond). A hydroxyl group of the tartaric acid forms another hydrogen bond with $\mathrm{HPO}_{4}{ }^{18}$ The main difference between $\mathrm{L}-(+)-$ and $\mathrm{D}-(-)$-Tar is that the hydroxyl group that interacts with brushite is different. In the former, the hydroxyl group is adjacent to the carboxyl group. In the latter, the hydroxyl group is located further back along the $\mathrm{C}-\mathrm{C}$ chain, resulting in a lengthier and weaker bond. Thus, D-(-)-Tar is unable to pin the [101] dynamic step and stop it from propagating. In contrast, $\mathrm{L}-(+)-\mathrm{Tar}$ does and inhibits mineral crystal growth. ${ }^{18,39}$ The theory behind this process is described in Figure 1

In the present study, we engineered collagen-brushite cements with much improved mechanical and biological properties by taking advantage of chiral Tar's ability to affect crystal subunit size. We demonstrate that even in the presence of collagen, $\mathrm{L}-(+)$-Tar decreases mineral crystal size, while D(-)-Tar fails to do so. This increases the fracture toughness of L-(+)-Tar- and not D-(-)-Tar-treated collagen-brushite cements. Thus, L-(+)-Tar allowed, for the first time, the production of collagen-brushite cements, which show enhanced biological and also mechanical properties compared to currently used brushite bioceramics.

\section{METHODS}

Composite Cement Preparation. Brushite cements were prepared using a standard protocol of a solid-liquid biphase reaction as described elsewhere. ${ }^{18} \beta$-tricalcium phosphate $(\beta$-TCP, $1.8 \mathrm{~g})$ $\mathrm{Ca}_{3}\left(\mathrm{PO}_{4}\right)_{2}$ (Sigma-Aldrich) was mixed with $1.2 \mathrm{~g}$ of monocalcium 
phosphate monohydrate (MCPM) $\mathrm{Ca}\left(\mathrm{H}_{2} \mathrm{PO}_{4}\right)_{2} \cdot \mathrm{H}_{2} \mathrm{O}$ (abcr GmbH, Germany) using a mortar and pestle until no clumps were visible. Gypsum $\mathrm{CaSO}_{4} \cdot \mathrm{H}_{2} \mathrm{O}$ was also used in some cases and was added to the powder mixture at $100,50,34,25,17,10,5$, and $0 \% \mathrm{w} / \mathrm{w}$. The cement's liquid phase was prepared by hydrating $(0.5,1,1.5$, and $2 \%$ $\mathrm{w} / \mathrm{v}$ ) bovine tendon powder (Collagen Solutions Ltd., U.K.) in $0.5 \mathrm{M}$ D-(-)-Tar and L-(+)-Tar overnight. Consequently, the mixture was homogenized using an IKA T18 Ultra-Turrax homogenizer (IKAWerke GmbH, Germany) for $5 \mathrm{~min}$ on ice (1 min on, $20 \mathrm{~s}$ off). For some samples, a mixture of NCPs purified from bovine bone was also mixed into the collagen suspension at a concentration of 150,100 , or $50 \mu \mathrm{g} / \mathrm{mL}$ (for the purification protocol, see section 2.2). Distilled water was used as the liquid phase in the control group. The cement reaction was induced by mixing, on a frozen glass slab using a spatula, the two phases at powder-to-liquid ratios $(\mathrm{P} / \mathrm{L})$ of $2.5,3,3.5,4$, and $4.3 \mathrm{~g} / \mathrm{mL}$. After a workable paste is formed, it was transferred to molds for further processing and left at room temperature for $30 \mathrm{~min}$. The set cements were removed from the molds and incubated in distilled water for $24 \mathrm{~h}$ at $37^{\circ} \mathrm{C}$.

NCP Purification. Cortical bone was obtained from veal shank cross sections. The bone was cleaned from muscle and bone marrow and broken up into $1 \mathrm{~g}$ pieces. After freezing them in liquid nitrogen, they were ground into a powder using a biopulverizer (Biospec Products). The organic phase of bone is primarily collagenous with small amounts of NCPs. Thus, the collagenous phase was removed before the NCPs as described elsewhere. ${ }^{40}$ To extract collagen type I, the bone powder was incubated at $4{ }^{\circ} \mathrm{C}$ on a rotor in $4 \mathrm{M}$ guanidine$\mathrm{HCl}$ in a $50 \mathrm{mM}$ Tris- $\mathrm{HCl}$ buffer $(\mathrm{pH} 7.4)$ for $48 \mathrm{~h}(50 \mathrm{~mL} / \mathrm{g}$ of bone). The supernatant was removed daily by centrifuging at $1000 \mathrm{~g}$ for $15 \mathrm{~min}$ and stored at $4{ }^{\circ} \mathrm{C}$ for later use. NCPs were then extracted by incubating the remaining bone powder pellet in $0.5 \mathrm{M}$ ethylenediaminetetraacetic acid (EDTA) in $50 \mathrm{mM}$ Tris- $\mathrm{HCl}$ (pH 7.4) at $4{ }^{\circ} \mathrm{C}$ for $48 \mathrm{~h}$ again removing and storing the supernatant daily. To prevent protein breakdown, extraction buffers were supplemented with a protease inhibitor cocktail $(100 \mathrm{mg} / \mathrm{mL}$ benzamidine, $1 \mathrm{mg} /$ $\mathrm{mL}$ leupeptin, and $0.05 \mathrm{M}$ phenylmethylsulfonyl fluoride). The NCP extract from both days was combined and concentrated using a Centricon Amicon Ultra 15, Ultracel 10k centrifugal filter (10 kDa cutoff) (Merck Millipore, Ireland). Consequently, the concentrate buffer was changed to $5 \mathrm{mM}$ ammonium bicarbonate $\left(\mathrm{NH}_{4} \mathrm{HCO}_{3}\right)$ at $\mathrm{pH} 8$, which supercharged NCPs to allow easier detection using mass spectrometry. ${ }^{41}$ All reagents, unless otherwise stated, were acquired from Sigma-Aldrich.

Proteomic Analysis: Liquid Chromatography-Mass Spectrometry (LC-MS). The NCP-containing extract was analyzed using a Thermo Scientific Ultimate 3000 HPLC and Orbital Fusion MS, quadrupole-Orbitrap-linear ion trap hybrid (Thermo Scientific) for 1 h. Data was visualized using Scaffold (Proteome Software Inc.) (Supporting Information Table S1). Pathway enrichment analysis to determine the biological pathways of the identified NCPs was carried out using the Reactome plug-in of Cytoscape (Institute of Systems Biology) (Supporting Information Table S2).

Fracture Toughness Testing. Cement specimens for testing were rectangular with a $\mathrm{V}$-shaped notch at the center $(20 \mathrm{~mm}$ length, $4 \mathrm{~mm}$ width, $2 \mathrm{~mm}$ thickness, $1.6 \mathrm{~mm}$ deep notch). Before testing, each specimen was submerged in a water bath at $37{ }^{\circ} \mathrm{C}$ for $24 \mathrm{~h}$. Fracture toughness was determined according to a three-point bend test (ASTM specification E 399-90, single-edged V-notch beam (SEVNB) loaded in the transverse direction) carried out on a MACH-1 system (McGill University, Canada) using a $25 \mathrm{~kg}$ load cell and a speed of $0.3 \mathrm{~mm} / \mathrm{min}$ (ASTM spec C 1421-10).

The equation used to calculate the fracture toughness was the following

$$
K_{\mathrm{IC}}=\frac{P_{\mathrm{Q}} S}{B W^{3 / 2}} \times f\left(\frac{a}{W}\right)
$$

where

$$
\begin{aligned}
f\left(\frac{a}{W}\right)= & 3 \sqrt{\frac{a}{W}} \\
& \times \frac{1.99-\left(\frac{a}{W}\right)\left(1-\frac{a}{W}\right)\left[2.15-3.93 \frac{a}{W}+2.7\left(\frac{a}{W}\right)^{2}\right]}{2\left(1+2 \frac{a}{W}\right)\left(1-\frac{a}{W}\right)^{3 / 2}}
\end{aligned}
$$

for which $K_{\mathrm{IC}}=$ fracture toughness $\left(\mathrm{MPa} \cdot \mathrm{m}^{1 / 2}\right), P_{\mathrm{Q}}=$ maximum force $(\mathrm{N}), S=$ support $\operatorname{span}(\mathrm{m}), B=$ specimen thickness $(\mathrm{m}), W=$ specimen width $(\mathrm{m})$, and $a=$ notch length $(\mathrm{m})$.

The SEVNB was preferred over other methods because it is a reproducible, inexpensive, and widely accepted method for testing porous ceramics. ${ }^{18}$ As ceramics are very brittle materials with very low strain to failure, only $P_{\mathrm{Q}}$ and not strain is considered when calculating $K_{\mathrm{IC}}$. Nevertheless, the area under the force-displacement graphs were calculated for some specimens to examine the impact of collagen on cement ductility.

Compressive Strength Testing. Cylindrical specimens $(6 \mathrm{~mm}$ diameter, $12 \mathrm{~mm}$ in length) were prepared using a Teflon mold. To ensure they are flush on both sides, they were polished using 600 and then 800 grit paper. Before testing, each specimen was submerged in a water bath at $37^{\circ} \mathrm{C}$ for $24 \mathrm{~h}$. The compression test was carried out using a $2 \mathrm{kN}$ Zwick Roell static material testing machine (Zwick Roell, Germany) at a compression head movement of $0.3 \mathrm{~mm} / \mathrm{min}$.

X-ray Diffraction (XRD). The cements produced were examined using an X-ray diffractometer (D8 Discovery Bruker AXS, Karlsruhe, Germany), with a copper source at $40 \mathrm{kV}$ and $40 \mathrm{~mA}$, to understand the impact of chiral Tar on the mineral crystals of the material. The diffraction spectra were obtained by measuring four frames with $300 \mathrm{~s}$ per frame $(\lambda=1.54056)$. EVA software (Bruker AXS, Karlsruhe, Germany) was used to identify the compounds present in the cements, and a python script was used to visualize the data obtained.

Fourier-Transform Infrared Spectroscopy (FTIR). The cements produced were analyzed using an FTIR spectrometer (PerkinElmer, Liantrisant, U.K.) to see if there is any interaction between chiral Tar and the brushite mineral. Cement pieces were ground up into a powder and placed onto the pedestal of the device. A transmittance spectrum was obtained using a wavelength range of $400-4000 \mathrm{~cm}^{-1}$ with a $1 \mathrm{~cm}^{-1}$ resolution. The resulting spectra were analyzed using the know-it-all software (Biorad, Hercules) and plotted using a python script.

Scanning Electron Microscopy (SEM). Mineral particle size was analyzed through images taken using an FEI Inspect F-50 FE-SEM operated at $10 \mathrm{kV}$ (FEI, Hillsboro). Sample conductivity was improved through sputter-coating a $4 \mathrm{~nm}$ layer of platinum using a Leica Microsystems EM ACE600 sputter coater (Leica Microsystems, Germany). The average crystal size was determined using a MATLAB (The MathWorks Inc., Natick) script.

Cell Culture. Human bone marrow mesenchymal stem cells (hMSCs) (PromoCell GmbH, Germany) were expanded and maintained in cell medium (Dulbecco's modified Eagle's medium (DMEM), 10\% fetal bovine serum (FBS), 1\% fungizone, $1 \%$ penicillin/streptomycin, $2 \mathrm{mM}$ L-glutamine, and $0.5 \%$ nonessential amino acids (NEEA) $(100 \times))$ at $37{ }^{\circ} \mathrm{C}$ with $5 \% \mathrm{CO}_{2}$ for 5 days in a $75 \mathrm{~cm}^{2}$ Corning culture flask. When $80 \%$ cells were confluent, they were trypsinized from the culture flask using trypsin-EDTA spun down at $1000 \mathrm{rpm}$ for 5 mins. Afterward, they were resuspended in media before further processing. All reagents were acquired from Sigma-Aldrich, U.K.

For cell attachment and morphology studies, cells were seeded onto the cements at a density of 5000 cells $/ \mathrm{cm}^{2}$ and incubated at 37 ${ }^{\circ} \mathrm{C}$ with $5 \% \mathrm{CO}_{2}$ in cell medium with no FBS for $4 \mathrm{~h}$ for cell attachment and morphology studies.

Immunostaining. Cells were then washed with warm $1 \times$ phosphate-buffered saline (PBS) twice before being fixed with $4 \%$ formaldehyde at room temperature for $15 \mathrm{~min}$ followed by permeabilization with a solution of $0.1 \%$ Triton X-100 in PBS at room temperature for $5 \mathrm{~min}$. To block nonspecific binding, the samples were incubated in $1 \%$ bovine serum albumin (BSA) in PBS 


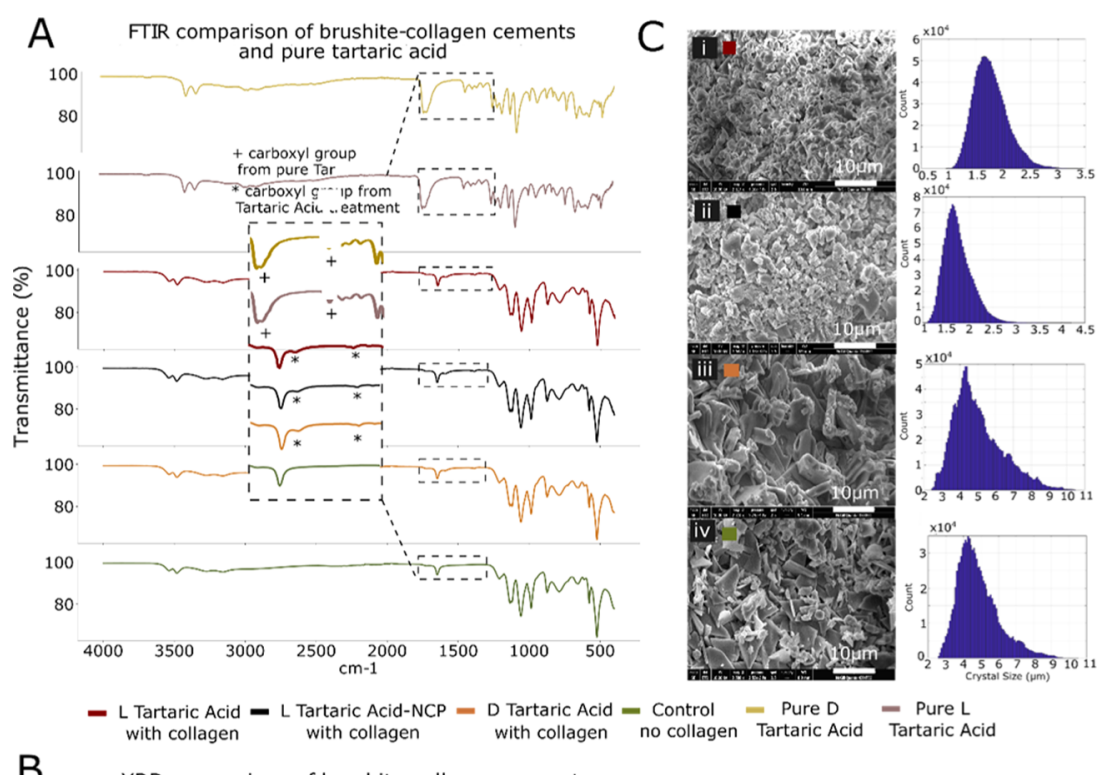

B XRD comparison of brushite-collagen cements

Brushite Particle Size in Cements
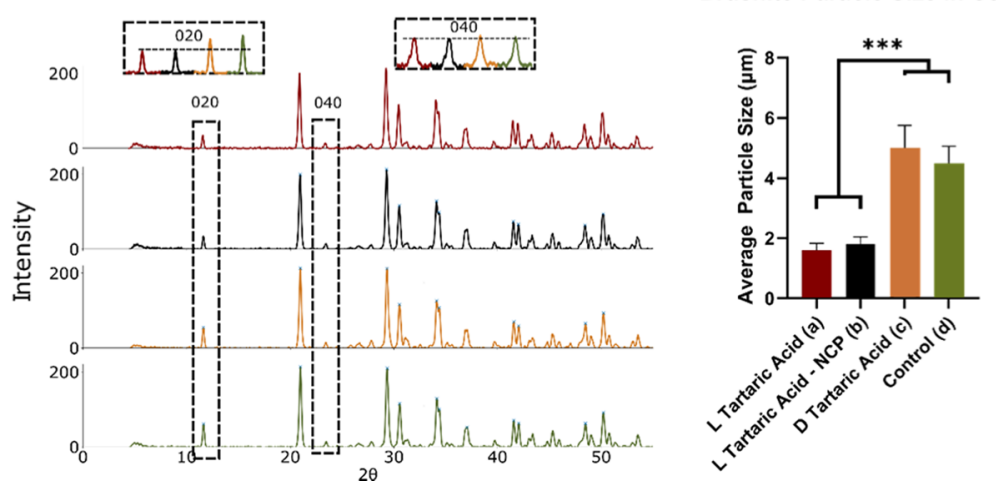

Figure 2. Summary of material characterization of brushite-collagen-NCP cements. (A) FTIR spectra of brushite cements produced conventionally (control) and brushite-collagen cements produced by adding L-(+) or D- $(-)$-Tar. Peaks associated with carboxyl groups in the $1400-1600 \mathrm{~cm}^{-1}$ range can be clearly seen in both tartaric acid groups but are absent in the control group. The peaks appear shifted compared to the carboxyl group peaks present in pure D and L Tar. (B) XRD spectrum of the $\mathrm{L}-(+)$-Tar group shows a decrease in peak intensity associated with the [010] plane of the brushite crystal compared to the control and D-(-)-Tar group. (C) SEM images and particle size analysis of the cements indicate that the particle size in the L- $(+)$-Tar groups (i, ii) is significantly smaller compared to the D-(-)-Tar (iii) and control (iv) groups. Legend: graph shows mean \pm standard deviation (SD), $n=4$ (images), multiple $t$-tests with $* * * p<0.001$.

for $1 \mathrm{~h}$ at room temperature. After blocking, an anti-vinculin mouse primary antibody at a dilution of 1:500 in 1\% BSA in PBS was added to the samples and incubated for $1 \mathrm{~h}$ at room temperature. The samples were consequently washed with $0.5 \%$ Tween 20 in PBS three times for $5 \mathrm{~min}$. A Cy3 anti-mouse secondary antibody (1:200) (Jackson ImmunoResearch Laboratories Inc.), Phalloidin Alexa Fluor 488 (1:100) (Thermofisher Scientific, U.K.) in 1\% BSA in PBS, was consequently added to the samples and incubated for $1 \mathrm{~h}$ at room temperature followed by another three $5 \mathrm{~min}$ washes with $0.5 \%$ Tween 20 in PBS. The nuclei of the cells were stained using Vectorshield-DAPI (Vector Laboratories) before being imaged with a fluorescent microscope (Zeiss, GmbH, Germany). All reagents unless otherwise stated were sourced from Sigma-Aldrich, U.K.

Statistical Analysis. Statistical significance $(P<0.05)$ between groups was shown using analysis of variance (ANOVA) and post-hoc paired $t$-tests between individual groups using GraphPad Prism 8 (GraphPad Software). Corrections for multiple comparisons were done using the Holm-Sidak method.

\section{RESULTS AND DISCUSSION}

Material Characterization of Brushite-Collagen Composite Cements with Tartaric Acid. The FTIR spectra of collagen-brushite cement samples treated with chiral Tar
(Figure 2A) show prominent carboxyl group peaks (COO-) at 1406 and $1589 \mathrm{~cm}^{-1},{ }^{42}$ which are absent in the control condition.

This suggests the participation of chiral Tar in the cement reaction where $\mathrm{COO}^{-}$interacts with the brushite crystal to form stable bonds. The equivalent carboxyl group peaks in pure Tar are observed at 1550 and $1740 \mathrm{~cm}^{-1}$, respectively ${ }^{18}$ (Figure 2). The shift in peaks confirms the formation of new interactions between Tar and brushite ${ }^{18}$ for both enantiomers of the molecule. The interaction of chiral Tar with brushite is consistent with previous findings ${ }^{18}$ and occurs despite the addition of collagen and NCPs. Strong brushite-associated phosphate peaks can be seen at 500-580 and 980-1130 $\mathrm{cm}^{-143}$ in all conditions, suggesting that the cement is indeed composed of brushite. To examine a possible brushitecollagen interaction, an in-depth analysis of the FTIR spectra was carried out. The FTIR spectrum of $\mathrm{L}-(+)-\mathrm{Tar}-$ brushite cement (no collagen) was subtracted from the spectra of $\mathrm{L}$ $(+)$-Tar-treated collagen-brushite cements at collagen concentrations of $0.5,1$, and $2 \% \mathrm{w} / \mathrm{v}$ to reduce background noise. The resulting spectra were compared to the FTIR spectra of 
pure collagen and the $\mathrm{L}-(+)-\mathrm{Tar}-$ brushite, no collagen, group (Figure 3).

In the $3600-2800 \mathrm{~cm}^{-1}$ range, pure brushite shows $-\mathrm{OH}$ stretching at $3536,3481,3270$, and $3154 \mathrm{~cm}^{-1}$ attributed to water in its structure. ${ }^{43}$ Pure collagen exhibits two major peaks in that range at 3300 and $2964 \mathrm{~cm}^{-1}$ associated with amide A

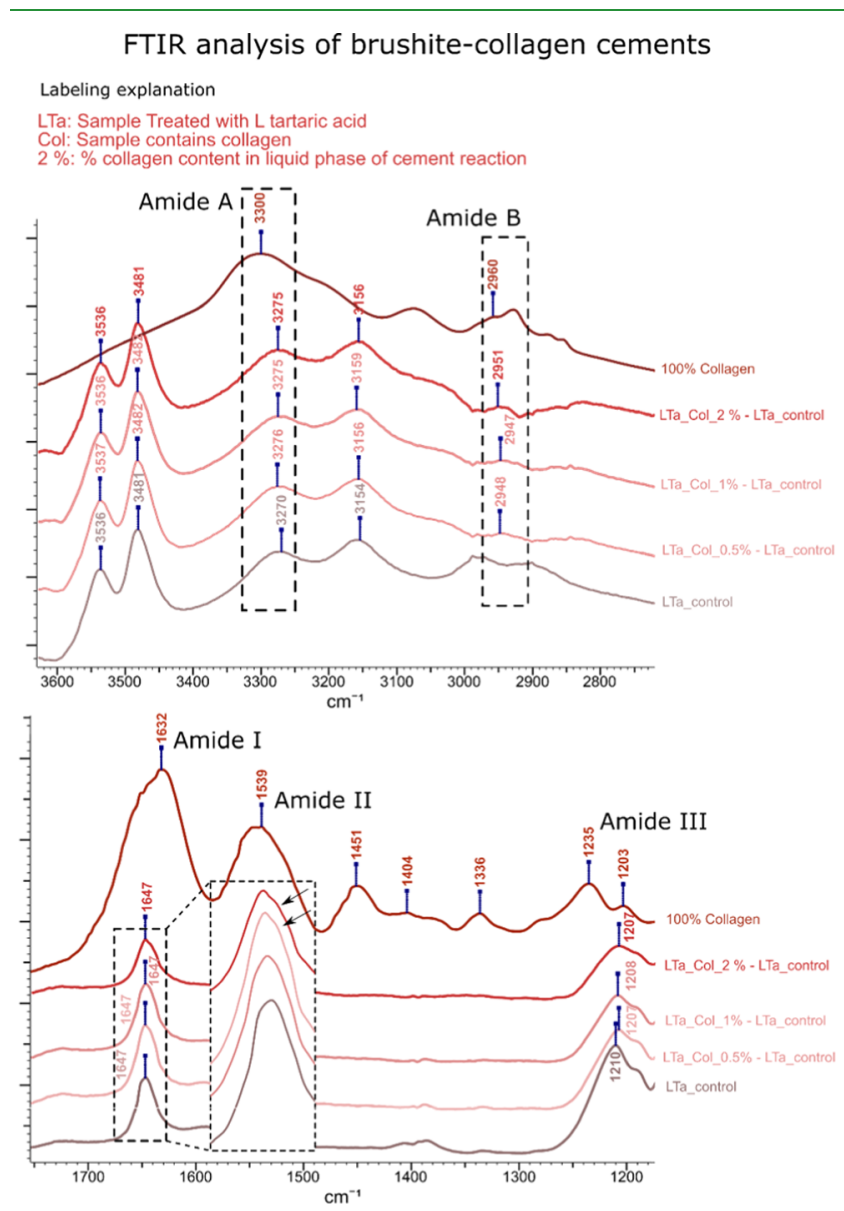

Figure 3. $2800-3600$ and $1200-1700 \mathrm{~cm}^{-1}$ ranges of the FTIR spectrum for pure $(100 \%)$ collagen, $\mathrm{L}-(+)$-Tar-treated plain brushite (LTa_control), and L-(+)-Tar-treated collagen-brushite cements (LTa_Col_0.5-2\%) (from which the L-(+)-Tar-treated plain brushite control spectrum (LTa_control) was subtracted). Amide A and B associated with $\mathrm{N}-\mathrm{H}$ stretching and asymmetrical $\mathrm{CH}_{2}$ stretching, respectively, are the main characteristic collagen peaks in the 2800$3600 \mathrm{~cm}^{-1}$ range. Pure brushite treated with $\mathrm{L}-(+)$-Tar shows four water-associated peaks. The four water peaks can also be seen in the modified (subtracted) FTIR spectra of L-(+)-Tar-treated collagencontaining brushite cements; however, one $\left(3275 \mathrm{~cm}^{-1}\right)$ is shifted toward the amide A peak, suggesting that it is a composite peak of amide A $\left(3300 \mathrm{~cm}^{-1}\right)$ and $-\mathrm{OH}$ stretch $\left(3270 \mathrm{~cm}^{-1}\right)$. The amide B peak at $2951 \mathrm{~cm}^{-1}$ can also be seen in the $\mathrm{L}-(+)$-Tar-treated collagenbrushite spectra. Within the $1200-1700 \mathrm{~cm}^{-1}$ range, the L- $(+)$-Tartreated collagen-brushite composite cements do not showcase characteristic amide II and III collagen peaks but show a characteristic amide I peak at $1647 \mathrm{~cm}^{-1}$ with a shoulder at $1640 \mathrm{~cm}^{-1}$ at higher collagen concentrations. The increased water-associated peaks in the composite cement samples despite the subtraction of control signify the existence of additional water in their structure likely due to collagen. (Note: Cements were stored in water and dried before analysis. However, some residual water might still have been present.) Legend: Label explanation; LTa (cement sample treated with L(+)-tartaric acid), Col (cement sample contains collagen), and 2\% (\% collagen content in the liquid phase of cement reaction).
(N-H stretching) and amide $\mathrm{B}\left(\mathrm{CH}_{2}\right.$ stretching $)$, respectively $^{44}$ (Figure 3). An amide A location at around $3300 \mathrm{~cm}^{-1}$ signifies increased involvement of collagen amides in hydrogen bonds. ${ }^{44}$ The modified (subtracted) spectra of the brushitecollagen cements show all water-associated $-\mathrm{OH}$ stretching peaks, suggesting that more water is present in its structure compared to control, likely because of collagen-mediated water retention. Importantly, the $3270 \mathrm{~cm}^{-1}$ peak is shifted to 3275 $\mathrm{cm}^{-1}$, toward the collagen amide A peak (Figure 3). A similar peak (at $3282 \mathrm{~cm}^{-1}$ ) is also observed in a brushite-collagen composite sponge containing a high amount of collagen (Supporting Information Figure 7), suggesting that the brushite-collagen cement peak at $3275 \mathrm{~cm}^{-1}$ is likely associated with amide collagen groups, which form bonds with the brushite mineral. An additional peak at $2950 \mathrm{~cm}^{-1}$ not observed in pure brushite but present in pure collagen can also be seen in the brushite-collagen cement groups, suggesting that collagen is indeed present.

In the $1700-1200 \mathrm{~cm}^{-1}$ FTIR spectrum range, brushite shows two water-associated peaks ( $-\mathrm{OH}$ bending) at 1647 and $1210 \mathrm{~cm}^{-1}$. ${ }^{43}$ Collagen showcases peaks associated with amide I (carbonyl stretching), amide II ( $\mathrm{N}-\mathrm{H}$ bending), and amide III (C-H stretching) at 1600-1700, 1539, and 1235 $\mathrm{cm}^{-1}$, respectively (Figure 3). ${ }^{44}$ The FTIR spectra of the collagen-brushite cements show peaks at 1647 and 1207 $\mathrm{cm}^{-1}$. This could be associated with additional water due to the presence of collagen, but particularly the peak at $1647 \mathrm{~cm}^{-1}$ could also signify $\mathrm{N}-\mathrm{H}$ bending (amide I). This is further evidenced when magnifying the region and observing a second shoulder placed at $1640 \mathrm{~cm}^{-1}$ particularly for brushite cements with higher collagen composition (Figure 3 ). The equivalent amide I peak for the brushite-collagen sponge is seen at 1638 $\mathrm{cm}^{-1}$ (Supporting Information Figure S7). The amide II and III peaks could not be observed in the collagen-brushite cement groups. However, amide II and III peaks are smaller than amide I and often harder to identify particularly when the collagen content is low.

Further evidence for the presence of collagen in the scaffold is revealed by an SEM image (Supporting Information Figure S1) of the cement. Collagen fibers and "sheets" interact with the brushite crystals. Further analysis of SEM images shows that $\mathrm{L}-(+)$-Tar effectively reduces the crystal size $(1.6 \pm 0.1$ $\mu \mathrm{m})$ of brushite, while $\mathrm{D}-(-)$-Tar, despite interacting with the mineral, does not have a considerable effect on the crystal size $(5 \pm 0.3 \mu \mathrm{m})$ compared to the control group $(4.5 \pm 0.2 \mu \mathrm{m})$ (Figure 1C).

From a morphological perspective, the crystals showed the typical trapezoidal shape with large $\{010\}$ faces in the control group (Figure 2Ciii). D-(-)-Tar did not alter the size significantly, but the particle edges appeared more rounded (Figure 2Civ). In the presence of L-(+)-Tar, brushite crystals exhibited a smaller, spheroid-like morphology without prominent $\{010\}$ faces (Figure $2 \mathrm{Ci}$ ). The addition of NCPs did not further decrease the crystal size $(1.8 \pm 0.1 \mu \mathrm{m})$ of brushite or affect its shape even at a concentration of $150 \mu \mathrm{g} /$ $\mathrm{mL}$ (Figure 2Cii) despite the literature suggesting that NCPs have a significant impact on mineralization. ${ }^{35}$ It is hard to pinpoint the exact reason, but it is likely that the cement reaction is too fast for NCPs to affect mineralization at a low concentration. A study using osteopontin, an NCP, confirmed the protein's ability to control mineralization using microliter amounts of reagent and allowing them to react for at least $48 \mathrm{~h}$. Very high nonphysiological amounts of NCPs might influence 

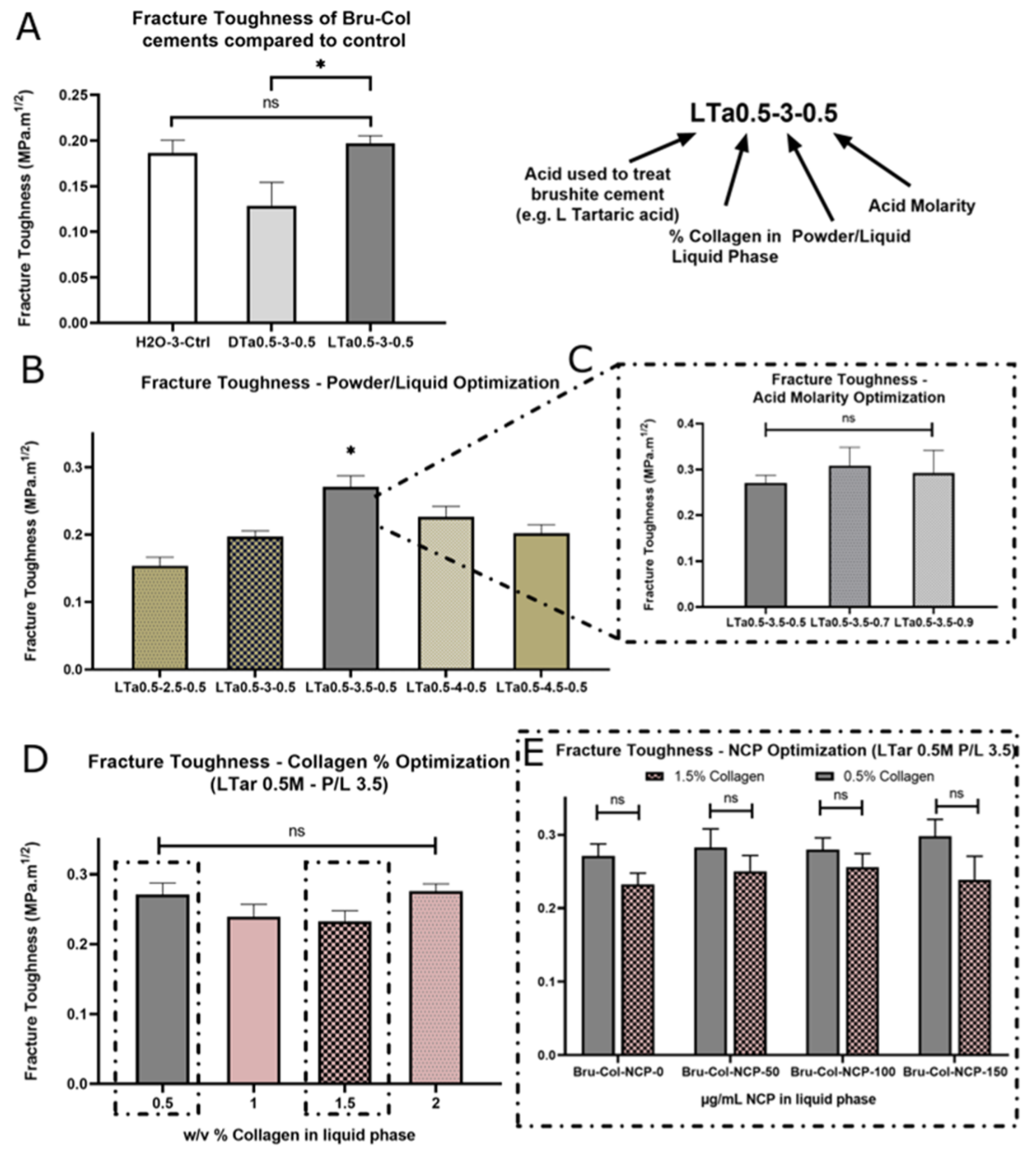

Figure 4. Graphs showing the mechanical optimization of brushite-collagen-noncollagenous protein (NCP) cements. (A) Comparison of the fracture toughness between conventionally produced plain brushite cements made with water $\left(\mathrm{H}_{2} \mathrm{O}-3\right.$-ctrl $)$ and brushite-collagen cements produced with $\mathrm{D}-(-)$ and $\mathrm{L}-(+)$-Tar. Optimization shows that brushite-collagen (bru-col) cements produced with $\mathrm{L}-(+)$-Tar have similar mechanical properties to control and significantly superior properties to the material produced with $\mathrm{D}-(-)-\mathrm{Tar}$ at a $\mathrm{P} / \mathrm{L}$ of 3 . Legend: explanation of the $x$ axis sample labeling notation. (B) Comparison of the fracture toughness of the L-(+)-Tar-treated collagen-brushite cement for different powder-to-liquid ratios. Optimization shows that a 3.5 powder/liquid ratio produces the toughest material (tougher than plain brushite cements). (C) Comparison of the fracture toughness of cements produced with different $\mathrm{L}-(+)$-Tar concentrations. Optimization shows no significant difference between groups. (D) Comparison of fracture toughness for different $\% \mathrm{w} / \mathrm{v}$ collagen in the liquid part of the L- $(+)$-Tar-treated brushitecollagen cements. Optimization shows no significant difference between groups. The 0.5 and $1.5 \% \mathrm{w} / \mathrm{v}$ collagen groups were chosen to explore the biological response of the brushite cements compared to control. The $2 \% \mathrm{w} / \mathrm{v}$ group was avoided due to manufacturing difficulties. (E) Comparison of the fracture toughness after incorporation of NCPs $(\mu \mathrm{g} / \mathrm{mL})$ in the liquid part of the cement reagents. Optimization shows no significant difference between groups. NCPs $(50 \mu \mathrm{g} / \mathrm{mL})$ were chosen for further experiments to examine potential biological benefits. Legend: graph shows mean \pm standard error of the mean (SEM), $n=5$, multiple $t$-tests with $* p<0.05$.

the cement reaction. However, producing them at that scale was not feasible in this study.

The XRD (Figure 2B) spectra of the cements treated with chiral Tar confirm that the crystal size of the L- $(+)$-Tar groups, as shown in the previous work, ${ }^{18}$ is due to $\mathrm{L}-(+)$-Tar binding to the $\{010\}$ face, inhibiting its growth. Thus, effectively reducing the ratio between the basal and side faces yields a smaller particle. The normalized XRD pattern shows attenuated peaks, i.e., $(020)$ and $(040)$, related to the $\{010\}$ face for the L(+)-Tar groups. This attenuation is not observed in the D(+)-Tar and control group. It should be noted that the brushite cement reaction is dependent on both the dissolution rate of $\beta$ TCP as well as brushite crystal growth. Previous studies showed $^{18}$ that the chiral selection described is not associated with the dissociation step of $\beta$-TCP during the cement reaction, but only to the brushite dynamic growth step. The dissociation step is the same for both enantiomers of Tar. ${ }^{18}$
The addition of collagen did not influence the brushite cement reaction, and all characteristic brushite peaks were present without additional ones. It has been suggested that collagen can starve the cement reaction of water due to its hydrophilicity, leading to remnant $\beta$-TCP and MCPM peaks, which signal an incomplete reaction. ${ }^{17}$ However, collagen was fully hydrated overnight and homogenized, alleviating the issue.

Improvement of Mechanical Properties. According to the Hall-Petch law, mechanical properties of hard ceramics are greatly increased if the crystal size is reduced. ${ }^{45}$ Controlling the crystal size of brushite cements with L-(+)-Tar should allow for the production of brushite-collagen cements with mechanical properties that do not compromise them in wet conditions and are superior to current brushite materials. Indeed, the fracture toughness of collagen-containing cements made with $\mathrm{L}-(+)$-Tar was not compromised in wet conditions 
compared to pure brushite at a $\mathrm{P} / \mathrm{L}$ of 3 . In contrast, the material prepared with $\mathrm{D}-(+)-\mathrm{Tar}$ showed significantly lower fracture toughness (Figure 4A) compared to the other two groups. Cements were also prepared using collagen suspended in $\mathrm{HCl}$ instead of Tar. However, these could not be tested as they were too brittle to be handled, suggesting that collagen has likely detrimental effects on cement integrity and strength. Collagen type I is highly hydrophilic. ${ }^{17,46}$ Wettability is essential for cell spreading and attachment ${ }^{47}$ but often leads to weaker mechanical properties of collagen-based biomaterials. $^{17,25}$ Interestingly, water is thought to increase fracture toughness in native bone ${ }^{48}$ by forming thin layers between adjacent mineral slabs as well as collagen fibers holding them together via capillary action while allowing some degree of movement. ${ }^{49,50}$ Indeed, capillary forces increase as the particle size decreases. ${ }^{51}$ Shape also affects capillary action with symmetric shapes, e.g., spheres, experiencing larger forces from water/air compared to tapered/nonsymmetrical shapes. ${ }^{51}$

In composite bioceramics, mineral particles are usually nonsymmetrical and randomly oriented. Thus, introducing water will destabilize the system particularly when a second phase such as hydrophilic collagen is introduced. This is the case for the D-(-)-Tar-treated condition (Figure 4C). In contrast, L-(+)-Tar creates small, spherelike particles, effectively increasing the interaction area and capillary forces between the phases and exhibiting adequate fracture toughness despite the introduction of collagen (Figure 4C).

Cement reactions with powder-to-liquid ratios $(\mathrm{P} / \mathrm{L})$ exceeding $3 \mathrm{~g} / \mathrm{mL}$, that were not possible for the plain brushite control group, were feasible for the L- $(+)$-Tar group due to the ability of $\mathrm{L}-(+)$-Tar to effectively reduce the mineral particle size of brushite-collagen cements, thus further improving the fracture toughness of the material. We show that as $\mathrm{P} / \mathrm{L}$ increases, so does the fracture toughness of the material up to a $\mathrm{P} / \mathrm{L}$ of 3.5 . At $3.5 \mathrm{~g} / \mathrm{mL}$, the fracture toughness of the materials was $0.27 \mathrm{MPa} . \mathrm{m}^{1 / 2}$, which to our knowledge is the toughest collagen-brushite cement to date (Figure 4B). Higher $\mathrm{P} / \mathrm{L}$ cements were possible, but their fracture toughness decreased as the cement mixture was increasingly hard to work with and to homogenize properly.

Tar molarity and collagen and NCP concentrations did not affect the fracture toughness of the cements (Figure 4C-E). Collagen concentrations higher than $2 \% \mathrm{w} / \mathrm{v}$ were not chosen as the liquid phase of the cement reaction was too viscous to work with. Taking the findings into consideration, L-(+)-Tartreated cements with a $\mathrm{P} / \mathrm{L}$ of $3.5, \mathrm{NCP}$ concentration of 50 $\mu \mathrm{g} / \mathrm{mL}$, and collagen concentrations of 0.5 and $1.5 \% \mathrm{w} / \mathrm{v}$ were picked for further biological characterization. The fracture toughness and compressive strength of the 0.5 and $1.5 \% \mathrm{w} / \mathrm{v}$ collagen $\mathrm{L}-(+)$-Tar-treated group were $\left(0.27 \pm 0.02 \mathrm{MPa} \cdot \mathrm{m}^{1 / 2}\right.$ and $13 \pm 2 \mathrm{MPa})$ and $\left(0.23 \pm 0.02 \mathrm{MPa} \cdot \mathrm{m}^{1 / 2}\right.$ and $10 \pm 1$ $\mathrm{MPa}$ ) in wet conditions, respectively. Comparatively, the pure brushite control group had a fracture toughness of $0.19 \pm 0.01$ $\mathrm{MPa}$ and compression strength of $8 \pm 1 \mathrm{MPa}$ (compression test results are shown in Supporting Information Figure 2). L(+)-Tar-treated collagen-brushite cements were also stiffer than control (plain brushite cement) (Supporting Information Figure 2).

The work until failure (area under the force-displacement curve) on the collagen-containing L-(+)-Tar-treated brushite cements was also significantly higher than on plain brushite cements, suggesting that the latter is more brittle and thus more prone to sudden failure (Supporting Information Figure S3).

Interestingly, when using gypsum powder, calcium sulfate, as the solid in the cement reaction instead of the brushite reagents, the fracture toughness of the collagen-bioceramic cements declined significantly (Supporting Information Figure S5) despite the use of $\mathrm{L}-(+)$-Tar, which has a similar effect on gypsum as brushite. ${ }^{52}$ This proposes that collagen has a unique interaction with calcium phosphates such as brushite, which is not the case for calcium sulfates. Researchers suggest ${ }^{53}$ that phosphate and sulfate both have similar amounts of binding sites on collagen as they likely interact with the same positively charged amino acids, namely, lysine and arginine. However, the study investigated phosphate and sulfate ions rather than their calcium salts. We could not find anything in the literature examining the interaction between gypsum and collagen, but it is well established that calcium phosphates such as hydroxyapatite (HA) bind strongly to collagen through the calcium ions in their lattice. ${ }^{54}$ This interaction is highly dependent on the calcium ion placement within the calcium phosphate lattice, ${ }^{55}$ which interact with aspartic and glutamic acid-rich motifs on collagen along the $\{100\}$ crystal plane ([001] vector). ${ }^{56}$ Brushite shows the same $\mathrm{Ca}^{2+}$ orientation as $\mathrm{HA}$ on the $\{100\}$ plane $^{57}$ and thus can interact with collagen on a plane other than $\{010\}$, which is occupied by chiral Tar. In contrast, gypsum has accessible calcium ions primarily along the $[101]$ growing step $(\{010\}$ plane $))^{52}$ which is already occupied by chiral Tar. This could explain why the two bioceramics behave so differently mechanically when collagen is introduced.

Addition of brushite into the L-(+)-Tar-treated gypsumcollagen cements restores its mechanical properties. The fracture toughness of L-(+)-Tar-treated gypsum-brushitecollagen cements was $0.32 \pm 0.07$ and $0.33 \pm 0.08 \mathrm{MPa} \cdot \mathrm{m}^{1 / 2}$ for 0.5 and $1.5 \% \mathrm{w} / \mathrm{v}$ collagen, respectively (Supporting Information Figure S5). The production of this second composite bioceramic might be of interest as its in vivo resorbability could likely be finely tuned. Gypsum resorbs faster than brushite, ${ }^{58}$ suggesting that their composite could exhibit a spectrum of resorption times.

Improvement of Biological Response. To test whether collagen incorporation into the L-(+)-Tar-treated brushite cements results in an improved hMSC response to the material, cell attachment and morphological analyses were carried out. Cells interact with collagen via the $\alpha 1 \beta 1, \alpha 2 \beta 1$, $\alpha 11 \beta 1$, or $\alpha 12 \beta 1$ integrin complexes. ${ }^{28}$ Integrin-mediated cell adhesions drive a complex process, which involves the formation of supramolecular structures, known as focal adhesions (FAs), involving proteins such as talin, vinculin, paxillin, FAK, and others. ${ }^{59}$ FAs are effectively the link between the cellular microenvironment and the extracellular matrix (ECM). This is essential for cell mechanosensing, i.e., allowing cells to respond to their environment based on forces they exert onto substrates (molecular clutch). ${ }^{59}$ Allowing hMSCs to respond to their environment can guide their fate and allows them to perform essential cell-related functions. ${ }^{59}$

In this study, cell adhesion was significantly higher in all L(+)-Tar-treated brushite cement groups containing collagen compared to the pure brushite control. After an initial seeding density of $5000,3000-5000$ cells $/ \mathrm{cm}^{2}$ were counted on collagen-containing cements, while only 1800 cells $/ \mathrm{cm}^{2}$ were counted on pure brushite after $4 \mathrm{~h}$ of culture without FBS (Supporting Information Figure S4). The addition of NCPs 
A

LTa0.5-3.5-0.5: Acid type used in cement reaction (e.g. L-(+)-Tartartic acid), $\%$ Collagen content in liquid phase of cement reaction-Powder/Liquid-Acid Molarity
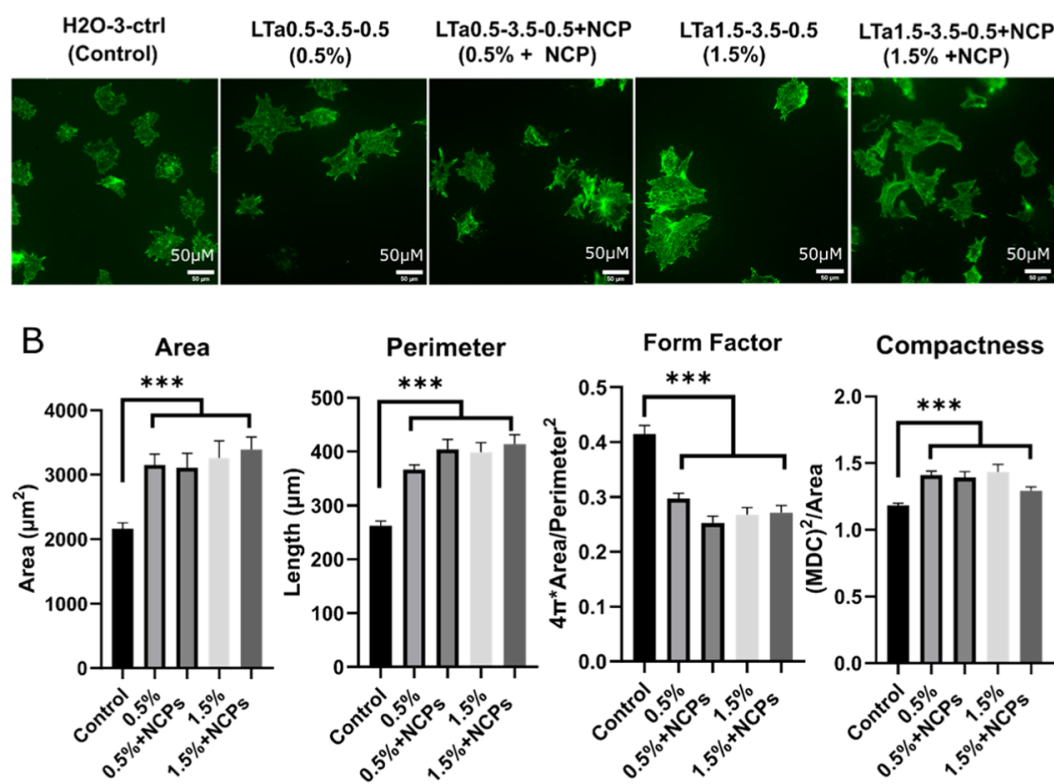

Compactness

C

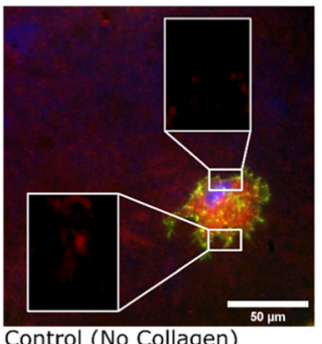

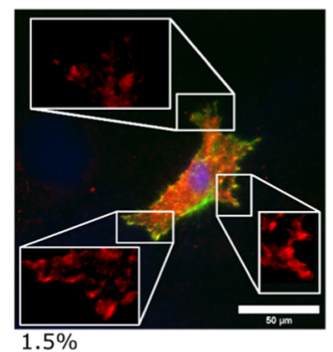

$1.5 \%$

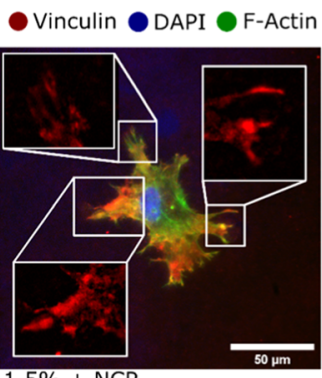

Figure 5. Human mesenchymal stem cell (hMSC) attachment studies carried out on brushite and brushite-collagen cements. Cells (5000) were seeded on each scaffold to allow for easier single-cell analysis. Cell morphology analysis (from 56 cells from triplicate material replicates) (A, B) revealed that collagen in the brushite cements treated with L-(+)-Tar significantly improved cell spreading and the formation of filopodia/ lamellipodia (cells become less circular). This can be seen in the graphs comparing cell area, perimeter, form factor, and compactness on L- $(+)-T a r-$ treated brushite cements with 0.5 and $1.5 \% w / v$ collagen content and plain brushite cement (control) samples. Although there is an increasing trend of cell spreading as the collagen content increases, that is not significant. Focal adhesion analysis (C) also reveals that introducing collagen to the L-(+)-Tar-treated brushite cements allows for the formation of integrin-mediated cell binding to the substrate (presence of distinct vinculin clusters). This is not the case when looking at the control group. Legend: graph shows mean \pm SEM, $n=56$ (cells), multiple $t$-tests with $* * * p<$ 0.001 .

did not further affect cell attachment. Cell morphology studies further revealed that even at low collagen concentrations cells exhibited greater spreading, i.e., higher area and perimeter on L-(+)-Tar-treated collagen-brushite cements compared to pure brushite. Cell circularity also decreased. In the L(+)-Tar-treated brushite-collagen cement groups, cells also formed more protrusions (lamellipodia and filopodia) away from the cell center compared to the control group (plain brushite cements) (compactness in collagen groups > compactness in brushite $>1$ perfect circle, form factor in collagen groups $<$ form factor in brushite $<1$ perfect circle) (Figure 5A,B). This is important as the ability of a cell to spread determines whether a cell proliferates, becomes quiescent, or dies. $^{60}$

A similar trend is observed on L-(+)-Tar-treated gypsumbrushite-collagen cements (Supporting Information Figure S6A,B), suggesting that the differences in cell morphology due to collagen can be observed on different, independently studied composite bioceramics. Interestingly, no cells could be identified on pure gypsum samples (Supporting Information Figure S6A,B). Comparatively, cells attached to pure brushite (Figure 5A,B) as well as gypsum-brushite cements (Supporting Information Figure $\mathrm{S} 6 \mathrm{~A}, \mathrm{~B}$ ) despite the absence of dedicated cell-binding domains, which are present in collagen. Nonspecific cell binding can occur due to electrostatic forces between cells and the substrate. ${ }^{61}$ In the absence of serum proteins as the $\zeta$-potential (measure of surface charge) approaches 0 , cells find it increasingly hard to attach. ${ }^{62}$ Gypsum has a $\zeta$-potential of $\sim-15 \mathrm{mV}^{63}$ while brushite has -30 to $-45 \mathrm{mV}$ at physiological $\mathrm{pH},{ }^{64,65}$ likely explaining the lack of cells present on the former.

The lack of specific cell-binding sites in the bioceramic-only samples is further shown through immunostaining of vinculin. Cement samples without collagen lack vinculin clusters overlapping with $\mathrm{F}$-actin at the cell periphery (Figure 5C and Supporting Information Figure S6C). In contrast, these are present in the collagen-containing groups with and without NCPs, suggesting that cells interact with the material through 
integrin binding (Figure 5C and Supporting Information Figure S6C).

\section{CONCLUSIONS}

This study demonstrates that chiral L-(+)-Tar can improve the mechanical properties of collagen-brushite cements in wet conditions via the inhibition of the [101] dynamic crystal growth step in contrast with $\mathrm{D}-(-)$-Tar, which does not have the same effect. The novel composite bioceramics achieve a significantly enhanced fracture toughness as high as $0.27 \mathrm{MPa}$. $\mathrm{m}^{1 / 2}$ and a compressive strength of $13 \mathrm{MPa}$ in wet conditions, which are well within the mechanical property range of cancellous bone (fracture toughness $0.1-0.8 \mathrm{MPa} \cdot \mathrm{m}^{1 / 2}$ and compressive strength $2-12 \mathrm{MPa}){ }^{66}$ Cell attachment, morphology, and cell-material interaction were improved in the collagen-bioceramic composites treated with L-(+)-Tar compared to the currently used pure bioceramics. Our work suggests that the involvement of chiral molecules, namely, L$(+)$-Tar, in the mineralization process allows the production of composite bioceramic materials with superior biological properties while still exhibiting impressive fracture toughness and compressive strength.

\section{ASSOCIATED CONTENT}

\section{s) Supporting Information}

The Supporting Information is available free of charge at https://pubs.acs.org/doi/10.1021/acsabm.0c00555.

Proteomic analysis of the NCP mixture; SEM of brushite-collagen cements treated with $\mathrm{L}-(+)-$ Tar acid; compression strength and stiffness of pure brushite cements and brushite-collagen-NCP $(50 \mu \mathrm{g} / \mathrm{mL})$ cements treated with $\mathrm{L}-(+)-$ Tar acid; cell number $/ \mathrm{mm}^{2}$ for brushite and brushite-collagen-NCP $(50 \mu \mathrm{g} / \mathrm{mL})$ cements treated with $\mathrm{L}-(+)-\mathrm{Tar}$; comparison of the fracture toughness between gypsum-collagen and brushite-collagen cements treated with $\mathrm{L}-(+)-$ Tar acid; additional human mesenchymal stem cell (hMSC) attachment studies; FTIR spectrum of collagenbrushite composite scaffold (PDF)

\section{AUTHOR INFORMATION}

\section{Corresponding Author}

Manuel Salmeron-Sanchez - Centre for the Cellular Microenvironment, University of Glasgow, Glasgow G12 8LT, United Kingdom; (1) orcid.org/0000-0002-8112-2100; Email: Manuel.Salmeron-Sanchez@glasgow.ac.uk

\section{Authors}

Stylianos O. Sarrigiannidis - Centre for the Cellular Microenvironment, University of Glasgow, Glasgow G12 8LT, United Kingdom; 이이이.org/0000-0002-5897-4137

Hanan Moussa - Faculty of Dentistry, McGill University, Montreal, Quebec H3A 2B2, Canada; Faculty of Dentistry, Benghazi University, Benghazi 9504, Libya; 10 orcid.org/ 0000-0001-6627-0247

Oana Dobre - Centre for the Cellular Microenvironment, University of Glasgow, Glasgow G12 8LT, United Kingdom

Matthew J. Dalby - Centre for the Cellular Microenvironment, University of Glasgow, Glasgow G12 8QQ, United Kingdom; (1) orcid.org/0000-0002-0528-3359
Faleh Tamimi - Faculty of Dentistry, McGill University, Montreal, Quebec H3A 2B2, Canada; College of Dental Medicine, Qatar University, Doha, Qatar

Complete contact information is available at: https://pubs.acs.org/10.1021/acsabm.0c00555

\section{Notes}

The authors declare no competing financial interest.

\section{ACKNOWLEDGMENTS}

This study was supported by Medical Research Scotland, Collagen Solutions Ltd., the University of Glasgow, EPSRC (EP/P001114/1), the Libyan Ministry of Education and Scientific Research, the Canadian Foundation for Innovation (CFI, F.T.), NSERC Discovery Grants RGPIN-418617-12 to F.T., and the Canada Research Chair program (F.T.). M.S.-S. acknowledge support from a grant from the U.K. Regenerative Medicine Platform "Acellular/Smart Materials-3D Architecture" (MR/R015651/1). The authors would also like to thank Collagen Solutions Ltd. for generously providing collagen for the study. Authors are thankful to Prof K.E. Tanner for helping secure funding for this project.

\section{REFERENCES}

(1) Do, A.-V.; Khorsand, B.; Geary, S. M.; Salem, A. K. 3D Printing of Scaffolds for Tissue Regeneration Applications. Adv. Healthcare Mater 2015, 4, 1742-1762.

(2) Habraken, W.; Habibovic, P.; Epple, M.; Bohner, M. Calcium Phosphates in Biomedical Applications: Materials for the Future? Mater. Today 2016, 19, 69-87.

(3) O’Brien, F. J. Biomaterials \& Scaffolds for Tissue Engineering. Mater. Today 2011, 14, 88-95.

(4) Van Heest, A.; Swiontkowski, M. Bone-Graft Substitutes. Lancet 1999, 353, S28-S29.

(5) Omelon, S. J.; Grynpas, M. D. Relationships between Polyphosphate Chemistry, Biochemistry and Apatite Biomineralization. Chem. Rev. 2008, 108, 4694-4715.

(6) Kamakura, S.; Sasano, Y.; Shimizu, T.; Hatori, K.; Suzuki, O.; Kagayama, M.; Motegi, K. Implanted Octacalcium Phosphate Is More Resorbable than $\beta$-Tricalcium Phosphate and Hydroxyapatite. J. Biomed. Mater. Res. 2002, 59, 29-34.

(7) Sheikh, Z.; Zhang, Y. L.; Tamimi, F.; Barralet, J. Effect of Processing Conditions of Dicalcium Phosphate Cements on Graft Resorption and Bone Formation. Acta Biomater. 2017, 53, 526-535.

(8) Kasten, P.; Luginbühl, R.; Van Griensven, M.; Barkhausen, T.; Krettek, C.; Bohner, M.; Bosch, U. Comparison of Human Bone Marrow Stromal Cells Seeded on Calcium-Deficient Hydroxyapatite, $\beta$-Tricalcium Phosphate and Demineralized Bone Matrix. Biomaterials 2003, 24, 2593-2603.

(9) Koepp, H. E.; Schorlemmer, S.; Kessler, S.; Brenner, R. E.; Claes, L.; Günther, K.-P.; Ignatius, Aa. Biocompatibility and Osseointegration of Beta-TCP: Histomorphological and Biomechanical Studies in a Weight-Bearing Sheep Model. J. Biomed. Mater. Res., Part B 2004, 70B, 209-217.

(10) Ripamonti, U. Osteoinduction in Porous Hydroxyapatite Implanted in Heterotopic Sites of Different Animal Models. Biomaterials 1996, 17, 31-35.

(11) Bose, S.; Roy, M.; Bandyopadhyay, A. Recent Advances in Bone Tissue Engineering Scaffolds. Trends Biotechnol. 2012, 30, 546-554.

(12) Ruano, R.; Jaeger, R. G.; Jaeger, M. M. Effect of a Ceramic and a Non-Ceramic Hydroxyapatite on Cell Growth and Procollagen Synthesis of Cultured Human Gingival Fibroblasts. J. Periodontol. 2000, 71, 540-545.

(13) Hing, K. A. Biomimetic Bone Regeneration, 57th ed.; Woodhead Publishing Limited, 2013. 
(14) Wopenka, B.; Pasteris, J. D. A Mineralogical Perspective on the Apatite in Bone. Mater. Sci. Eng., C 2005, 25, 131-143.

(15) Bang, L. T.; Ramesh, S.; Purbolaksono, J.; Long, B. D.; Chandran, H.; Ramesh, S.; Othman, R. Development of a Bone Substitute Material Based on Alpha-Tricalcium Phosphate Scaffold Coated with Carbonate Apatite/Poly-Epsilon-Caprolactone. Biomed. Mater. 2015, 10, No. 045011.

(16) Constantz, B. R.; Barr, B. M.; Ison, I. C.; Fulmer, M. T.; Baker, J.; McKinney, L. A.; Goodman, S. B.; Gunasekaren, S.; Delaney, D. C.; Ross, J.; Poser, R. D. Histological, Chemical, and Crystallographic Analysis of Four Calcium Phosphate Cements in Different Rabbit Osseous Sites. J. Biomed. Mater. Res. 1998, 43, 451-461.

(17) Tamimi, F.; Kumarasami, B.; Doillon, C.; Gbureck, U.; Le, D.; Lopez, E.; Barralet, J. E. Brushite - Collagen Composites for Bone Regeneration. Acta Biomater. 2008, 4, 1315-1321.

(18) Moussa, H.; Jiang, W.; Alsheghri, A.; Mansour, A.; El, A.; Pan, H.; Tang, R.; Song, J.; Vargas, J.; Mckee, M. D.; Tamimi, F. High Strength Brushite Bioceramics Obtained by Selective Regulation of Crystal Growth with Chiral Biomolecules. Acta Biomater. 2020, 106, 351-359.

(19) Donaldson, A. J.; Thomson, H. E.; Harper, N. J.; Kenny, N. W. Bone Cement Implantation Syndrome. Br. J. Anaesth. 2009, 102, 1222.

(20) Ricard-Blum, S. The Collagen Family. Cold Spring Harbor Perspect. Biol. 2011, 3, No. a004978.

(21) Niyibizi, C.; Eyre, D. R. Structural Characteristics of CrossLinking Sites in Type V Collagen of Bone: Chain Specificities and Heterotypic Links to Type I Collagen. Eur. J. Biochem. 1994, 224, 943-950.

(22) Viguet-Carrin, S.; Garnero, P.; Delmas, P. D. The Role of Collagen in Bone Strength. Osteoporosis Int. 2006, 17, 319-336.

(23) Kirsch, E.; Krieg, T.; Remberger, K.; Fendel, H.; Bruckner, P.; Muller, P. K. Disorder of Collagen Metabolism in a Patient with Osteogenesis Imperfecta (Lethal Type): Increased Degree of Hydroxylation of Lysine in Collagen Types I and III. Eur. J. Clin. Invest. 1981, 11, 39-47.

(24) Lynn, A. K.; Best, S. M.; Cameron, R. E.; Harley, B. A.; Yannas, I. V.; Gibson, L. J.; Bonfield, W. Design of a Multiphase Osteochondral Scaffold. I. Control of Chemical Composition. J. Biomed. Mater. Res. A 2010, 92A, 1057-1065.

(25) Harley, B. A.; Lynn, A. K.; Wissner-gross, Z.; Bonfield, W.; Yannas, I. V.; Gibson, L. J. Design of a Multiphase Osteochondral Scaffold. II. Fabrication of a Mineralized Collagen - Glycosaminoglycan Scaffold. J. Biomed. Mater. Res. A 2009, 92A, 1066-1077.

(26) Harley, B. A.; Lynn, A. K.; Wissner-gross, Z.; Bonfield, W.; Yannas, I. V.; Gibson, L. J. Design of a Multiphase Osteochondral Scaffold III: Fabrication of Layered Scaffolds with Continuous Interfaces. J. Biomed. Mater. Res. A 2009, 92A, 1078-1093.

(27) O’Brien, F. J.; Harley, B. A.; Yannas, I. V.; Gibson, L. J. The Effect of Pore Size on Cell Adhesion in Collagen-GAG Scaffolds. Biomaterials 2005, 26, 433-441.

(28) Zeltz, C.; Gullberg, D. The Integrin - Collagen Connection a Glue for Tissue Repair? J. Cell Sci. 2016, 129, 653-664.

(29) Glowacki, J.; Mizuno, S. Collagen Scaffolds for Tissue Engineering. Biopolymers 2008, 89, 338-344.

(30) Rho, J. Y.; Kuhn-Spearing, L.; Zioupos, P. Mechanical Properties and the Hierarchical Structure of Bone. Med. Eng. Phys. 1998, 20, 92-102.

(31) Alexander, B.; Daulton, T. L.; Genin, G. M.; Lipner, J.; Pasteris, J. D.; Wopenka, B.; Thomopoulos, S. The Nanometre-Scale Physiology of Bone: Steric Modelling and Scanning Transmission Electron Microscopy of Collagen-Mineral Structure. J. R. Soc. Interface 2012, 9, 1774-1786.

(32) Mellon, S. J.; Tanner, K. E. Bone and Its Adaptation to Mechanical Loading: A Review. Int. Mater. Rev. 2012, 57, 235-255.

(33) Addison, W. N.; Masica, D. L.; Gray, J. J.; McKee, M. D. Phosphorylation-Dependent Inhibition of Mineralization by Osteopontin ASARM Peptides Is Regulated by PHEX Cleavage. J. Bone Miner. Res. 2010, 25, 695-705.
(34) Boskey, A. L.; Maresca, M.; Ullrich, W.; Doty, S. B.; Butler, W. T.; Prince, C. W. Osteopontin-Hydroxyapatite Interactions in Vitro: Inhibition of Hydroxyapatite Formation and Growth in a Gelatin-Gel. Bone Miner. 1993, 22, 147-159.

(35) Hoac, B.; Nelea, V.; Jiang, W.; Kaartinen, M. T.; Mckee, M. D. Mineralization-Inhibiting Effects of Transglutaminase-Crosslinked Polymeric Osteopontin. Bone 2017, 101, 37-48.

(36) Rodriguez, D. E.; Thula-Mata, T.; Toro, E. J.; Yeh, Y.; Holt, C.; Holliday, L. S.; Gower, L. B. Multifunctional Role of Osteopontin in Directing Intrafibrillar Mineralization of Collagen and Activation of Osteoclasts. Acta Biomater. 2014, 10, 494-507.

(37) Jiang, W.; Pacella, M. S.; Athanasiadou, D.; Nelea, V.; Vali, H.; Hazen, R. M.; Gray, J. J.; Mckee, M. D. Chiral Acidic Amino Acids Induce Chiral Hierarchical Structure in Calcium Carbonate. Nat. Commun. 2017, 8, No. 15066.

(38) Jiang, W.; Pacella, M. S.; Vali, H.; Gray, J. J.; Mckee, M. D. Chiral Switching in Biomineral Suprastructures Induced by Homochiral 1 -Amino Acid. Sci. Adv. 2018, 4, No. eaas9819.

(39) Jiang, W.; et al. Switchable Chiral Selection of Aspartic Acids by Dynamic States of Brushite. J. Am. Chem. Soc. 2017, 139, 8562-8569.

(40) Mansour, A.; Abu-nada, L.; Al-waeli, H.; Amine, M.; Abdallah, M.; Kinsella, J. M.; Kort-mascort, J.; Henderson, J. E.; Ramirezgarcialuna, J. L.; Tran, S. D.; Elkashty, O. A.; Mousa, A.; El-hadad, A. A.; Taqi, D.; Al-hamad, F.; Alageel, O.; Kaartinen, M. T.; Tamimi, F. Bone Extracts Immunomodulate and Enhance the Regenerative Performance of Dicalcium Phosphates Bioceramics. Acta Biomater. 2019, 89, 343-358.

(41) Cassou, C. A.; Sterling, H. J.; Susa, A. C.; Williams, E. R. Electrothermal Supercharging in Mass Spectrometry and Tandem Mass Spectrometry of Native Proteins. Anal. Chem. 2013, 85, 138146.

(42) Kolev, T.; Spiteller, M.; Koleva, B. Spectroscopic and Structural Elucidation of Amino Acid Derivatives and Small Peptides: Experimental and Theoretical Tools. Amino Acids 2010, 38, 45-50.

(43) Idowu, B.; Cama, G.; Deb, S.; Silvio, L. Di. In Vitro Osteoinductive Potential of Porous Monetite for Bone Tissue Engineering. J. Tissue Eng. 2014, 5, No. 204173141453657.

(44) Nagai, T.; Suzuki, N.; Tanoue, Y.; Kai, N. Collagen from Tendon of Yezo Sika Deer (Cervus Nippon Yesoensis) as By-Product. Food Nutr. Sci. 2012, 03, 72-79.

(45) Abdallah, M.; Eimar, H.; Bassett, D. C.; Schnabel, M.; Ciobanu, O.; Nelea, V.; Mckee, M. D.; Cerruti, M.; Tamimi, F. DiagenesisInspired Reaction of Magnesium Ions with Surface Enamel Mineral Modifies Properties of Human Teeth. Acta Biomater. 2016, 37, 174183.

(46) Oliveira, S. M.; Ringshia, R. A.; Legeros, R. Z.; Clark, E.; Yost, M. J.; Terracio, L.; Teixeira, C. C. An Improved Collagen Scaffold for Skeletal Regeneration. J. Biomed. Mater. Res. A 2010, 94, 371-379.

(47) D’Elía, N. L.; Mathieu, C.; Hoemann, C. D.; Laiuppa, J. A.; Santillán, G. E.; Messina, P. V. Bone-Repair Properties of Biodegradable Hydroxyapatite Nano-Rod Superstructures. Nanoscale 2015, 7, 18751-18762.

(48) Nyman, J. S.; Roy, A.; Shen, X.; Acuna, R. L.; Tyler, J. H.; Wang, $\mathrm{X}$. The Influence of Water Removal on the Strength and Toughness of Cortical Bone. J. Biomech. 2006, 39, 931-938.

(49) Duer, M.; Veis, A. Bone Mineralization: Water Brings Order. Nat. Mater. 2013, 12, 1081-1082.

(50) Wang, Y.; Von Euw, S.; Fernandes, F. M.; Cassaignon, S.; Selmane, M.; Laurent, G.; Pehau-Arnaudet, G.; Coelho, C.; Bonhomme-Coury, L.; Giraud-Guille, M. M.; Babonneau, F.; Azaïs, T.; Nassif, N. Water-Mediated Structuring of Bone Apatite. Nat. Mater. 2013, 12, 1144-1153.

(51) Chatterjee, N.; Flury, M. Effect of Particle Shape on Capillary Forces Acting on Particles at the Air-Water Interface. Langmuir 2013, 29, 7903-7911.

(52) Chen, W.; Zhao, W.; Wu, Y.; Wang, Y.; Zhang, B.; Li, F.; Chen, Q.; Qi, Z.; Xu, Z. Origin of Gypsum Growth Habit Difference as Revealed by Molecular Conformations of Surfacebound Citrate and Tartrate. CrystEngComm 2018, 20, 3581-3589. 
(53) Mertz, E. L.; Leikin, S. Interactions of Inorganic Phosphate and Sulfate Anions with Collagen. Biochemisty 2004, 43, 14901-14912.

(54) Ehrlich, H.; Hanke, T.; Simon, P.; Born, R.; Fischer, C.; Frolov, A.; Langrock, T.; Hoffmann, R.; Schwarzenbolz, U.; Henle, T.; Bazhenov, V. V.; Worch, H. Carboxymethylation of the Fibrillar Collagen with Respect to Formation of Hydroxyapatite. J. Biomed. Mater. Res., Part B 2010, 92, 542-551.

(55) Kikuchi, M.; Ikoma, T.; Itoh, S.; Matsumoto, H. N.; Koyama, Y.; Takakuda, K.; Shinomiya, K.; Tanaka, J. Biomimetic Synthesis of Bone-like Nanocomposites Using the Self-Organization Mechanism of Hydroxyapatite and Collagen. Compos. Sci. Technol. 2004, 64, 819825.

(56) Tao, J.; Battle, K. C.; Pan, H.; Salter, E. A.; Chien, Y. C.; Wierzbicki, A.; De Yoreo, J. J. Energetic Basis for the Molecular-Scale Organization of Bone. Proc. Natl. Acad. Sci. U.S.A. 2015, 112, 326331.

(57) Gashti, M. P.; Bourquin, M.; Stir, M.; Hulliger, J. Glutamic Acid Inducing Kidney Stone Biomimicry by a Brushite/Gelatin Composite. J. Mater. Chem. B 2013, 1, 1501-1508.

(58) Vernon, B. Injectable. In Biomaterials, 1st ed.; Woodhead Publishing Limited: Cambridge, U.K., 2011.

(59) Cantini, M.; Donnelly, H.; Dalby, M. J.; Salmeron-Sanchez, M. The Plot Thickens: The Emerging Role of Matrix Viscosity in Cell Mechanotransduction. Adv. Healthcare Mater. 2019, 9, No. 1901259.

(60) Mcgrath, J. L. Cell Spreading: The Power to Simplify. Curr. Biol. 2007, 17, 357-358.

(61) Hoshiba, T.; Yoshikawa, C.; Sakakibara, K. Characterization of Initial Cell Adhesion on Charged Polymer Substrates in SerumContaining and Serum-Free Media. Langmuir 2018, 34, 4043-4051.

(62) Altankov, G.; Richau, K.; Groth, T. The Role of Surface Zeta Potential and Substratum Chemistry for Regulation of Dermal Fibroblasts Interaction. Materialwiss. Werkstofftech. 2003, 34, 11201128.

(63) Hatagawa, M. Measurement and Application of Mtf. Jpn. J. Radiol. Technol. 1994, 50, 1872-1887.

(64) Chen, H.; Chang, H.; Ko, H.; Hung, I. Effects of Solute and Surfactant Addition on the Crystallization and Morphology of Hydroxyapatite Powders Synthesized by Hydrolysis of Calcium Hydrogen Phosphate Dehydrate (DCPD). Metall. Mater. Trans. A 2013, 44, 1023-1033.

(65) Gbureck, U.; Probst, J.; Thull, R. Surface Properties of Calcium Phosphate Particles for Self Setting Bone Cements. Biomol. Eng. 2002, $19,51-55$.

(66) Fu, Q.; Saiz, E.; Rahaman, M. N.; Tomsia, A. P. Bioactive Glass Scaffolds for Bone Tissue Engineering: State of the Art and Future Perspectives. Mater. Sci. Eng., C 2011, 31, 1245-1256. 